\title{
Front Matter: Volume 6835
}

, "Front Matter: Volume 6835," Proc. SPIE 6835, Infrared Materials, Devices, and Applications, 683501 (31 January 2008); doi: 10.1117/12.785146

SPIE. Event: Photonics Asia 2007, 2007, Beijing, China 


\section{PROCEEDINGS OF SPIE}

\section{Infrared Materials, Devices, and Applications}

Yi Cai

Haimei Gong

Jean-Pierre Chatard

Editors

\section{2-15 November 2007 \\ Beijing, China}

Sponsored by

SPIE - COS-Chinese Optical Society

Cooperating Organizations

OSJ-Optical Society of Japan - OSK-Optical Society of Korea - Australian Optical Society • Optical Society of Singapore $\cdot$ Beijing Institute of Technology (China) $\bullet$ Beijing University of Posts and Telecommunication (China) • Peking University (China) • Tsinghua University (China) • Zhejiang University (China) • Changchun University of Science and Technology (China) • University of Shanghai for Science and Technology (China) • Shanghai Jiao Tong University (China) • Tianjin University (China) Nankai University (China) - Shanghai Institute of Optics and Fine Mechanics (China) • Changchun Institute of Optics and Fine Mechanics (China) • Institute of Semiconductors (China) • Institute of Optics and Electronics (China) - Shanghai Institute of Technical Physics (China) • China Instrument and Control Society • China Solid State Lighting Research and Industry Alliance • Optoelectronics Technology Committee, cos (China)

Supporting Organizations

CAST_China Association for Science and Technology (China) - NNSF-National Nature Science Foundation (China) • The Ministry of Science and Technology (China)

Published by

SPIE

Volume 6835 
The papers included in this volume were part of the technical conference cited on the cover and title page. Papers were selected and subject to review by the editors and conference program committee. Some conference presentations may not be available for publication. The papers published in these proceedings reflect the work and thoughts of the authors and are published herein as submitted. The publisher is not responsible for the validity of the information or for any outcomes resulting from reliance thereon.

Please use the following format to cite material from this book:

Author(s), "Title of Paper," in Infrared Materials, Devices, and Applications, edited by Yi Cai, Haimei Gong, Jean-Pierre Chatard, Proceedings of SPIE Vol. 6835 (SPIE, Bellingham, WA, 2007) Article CID Number.

ISSN 0277-786X

ISBN 9780819470102

Published by

SPIE

P.O. Box 10, Bellingham, Washington $98227-0010$ USA

Telephone +1 3606763290 (Pacific Time) · Fax +1 3606471445

SPIE.org

Copyright (c) 2007, Society of Photo-Optical Instrumentation Engineers

Copying of material in this book for internal or personal use, or for the internal or personal use of specific clients, beyond the fair use provisions granted by the U.S. Copyright Law is authorized by SPIE subject to payment of copying fees. The Transactional Reporting Service base fee for this volume is $\$ 18.00$ per article (or portion thereof), which should be paid directly to the Copyright Clearance Center (CCC), 222 Rosewood Drive, Danvers, MA 01923. Payment may also be made electronically through CCC Online at copyright.com. Other copying for republication, resale, advertising or promotion, or any form of systematic or multiple reproduction of any material in this book is prohibited except with permission in writing from the publisher. The CCC fee code is $0277-786 \mathrm{X} / 07 / \$ 18.00$.

Printed in the United States of America.

Publication of record for individual papers is online in the SPIE Digital Library.

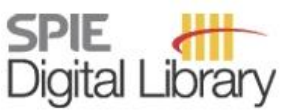

SPIEDigitalLibrary.org

Paper Numbering: Proceedings of SPIE follow an e-First publication model, with papers published first online and then in print and on CD-ROM. Papers are published as they are submitted and meet publication criteria. A unique, consistent, permanent citation identifier (CID) number is assigned to each article at the time of the first publication. Utilization of CIDs allows articles to be fully citable as soon they are published online, and connects the same identifier to all online, print, and electronic versions of the publication. SPIE uses a six-digit CID article numbering system in which:

- The first four digits correspond to the SPIE volume number.

- The last two digits indicate publication order within the volume using a Base 36 numbering system employing both numerals and letters. These two-number sets start with $00,01,02,03,04,05$, $06,07,08,09,0 \mathrm{~A}, 0 \mathrm{~B} \ldots \mathrm{OZ}$, followed by 10-1Z, 20-2Z, etc.

The CID number appears on each page of the manuscript. The complete citation is used on the first page, and an abbreviated version on subsequent pages. Numbers in the index correspond to the last two digits of the six-digit CID number. 


\section{Contents}

$\begin{aligned} \text { xi } & \text { Conference Committee } \\ \text { xiii } & \text { Symposium Committees }\end{aligned}$

INFRARED MATERIALS/DEVICES AND THEIR APPLICATION I

683502 New architecture for TECless operation of uncooled microbolometers developed at LETI (Invited Paper) [6835-74]

F. Simoens, CEA-LETI-MINATEC-SLIR (France); M. Tchagaspanian, CEA-LETI-MINATEC-DCIS (France); A. Arnaud, P. Imperinetti, CEA-LETI-MINATEC-SLIR (France); G. Chammings, CEALETI-MINATEC-DCIS (France); J. J. Yon, CEA-LETI-MINATEC-SLIR (France); J. L. Tissot, ULIS (France); G. Destefanis, CEA-LETI-MINATEC-SLIR (France)

683504 New concept system research and development base on advanced infrared detector [6835-26]

Q. Ding, H. Liu, Luoyang Institute of Electro-Optical Equipment of AVIC (China)

$683505256 \times 1$ element linear InGaAs short wavelength near-infrared detector arrays [6835-27]

X. Li, H. Tang, G. Fan, D. Liu, X. Shao, Shanghai Institute of Technical Physics (China);

Y. Zhang, Shanghai Institute of Microsystem and Information Technology (China);

H. Zhang, X. Chen, S. Zhu, H. Gong, J. Fang, Shanghai Institute of Technical Physics (China)

683506 Performance analysis of 256 element linear $2.4 \mu \mathrm{m}$ InGaAs photovoltaic detector arrays [6835-29]

K. Zhang, H. Tang, X. Wu, Shanghai Institute of Technical Physics (China) and Graduate School of the Chinese Academy of Sciences (China); X. Li, Shanghai Institute of Technical Physics (China); Y. Zhang, Shanghai Institute of Microsystem and Information Technology (China); H. Gong, Shanghai Institute of Technical Physics (China)

\section{INFRARED MATERIALS/DEVICES AND THEIR APPLICATION III}

6835 OA Near-infrared photodetectors based on mercury indium telluride single crystals (Invited Paper) [6835-48]

X. Zhang, W. Sun, Northwestern Polytechnical Univ. (China) and Luoyang Optoelectronic Institute (China); Z. Lu, L. Zhang, L. Zhao, J. Ding, G. Yan, Luoyang Optoelectronic Institute (China)

6835 OB Performance and reliability characteristic of Stirling cryocoolers [6835-40]

X. G. Liu, Y. N. Wu, L. He, Shanghai Institute of Technical Physics (China)

6835 OC Spatial light modulator based on sheared polymer network liquid crystal [6835-50]

Y. Luo, J. Gao, Xi'an Applied Optics Institute (China)

$6835 \mathrm{OD}$ Properties of $\mathrm{Au} / \mathrm{Pt} / \mathrm{Ti}$ contact to $\mathrm{p}-\mathrm{InP}$ by rapid thermal processing [6835-56]

Y. LV, Luoyang Optoelectronic Institute (China); H. Tang, B. Han, X. Wu, K. Zhang, X. Li,

H. Gong, Shanghai Institute of Technical Physics (China) 
6835 OE A novel vibration control system for Stirling cryocoolers [6835-62]

B. Yang, Y. Wu, Y. Tang, H. Fu, G. Lu, G. Chen, Shanghai Institute of Technical Physics

(China)

\section{INFRARED MATERIALS/DEVICES AND THEIR APPLICATION IV}

6835 OF Uncooled amorphous silicon 160×120 IRFPA with $25 \mu \mathrm{m}$ pixel-pitch for large volume applications (Invited Paper) [6835-105]

M. Vilain, J. L. Tissot, O. Legras, ULIS (France); J. J. Yon, CEA-LETI (France); C. Minassian,

B. Fièque, J. M. Chiappa, ULIS (France)

6835 OG Innovative on-chip packaging applied to uncooled IRFPA [6835-63]

G. Dumont, A. Arnaud, P. Imperinetti, E. Mottin, F. Simoens, C. Vialle, W. Rabaud, G. Grand, N. Baclet, CEA-LETI, MINATEC (France)

$6835 \mathrm{OH}$ Design and simulation of a 512×1 readout circuit for focal plane array [6835-76]

Y. Li, H. Zhu, X. Li, J. Ding, J. Fang, Shanghai Institute of Technical Physics (China)

$6835 \mathrm{Ol}$ The formation and elimination of inclusions in CdZnTe crystal [6835-79]

C. Liu, Shanghai Institute of Technical Physics (China)

\section{INFRARED MATERIALS/DEVICES AND THEIR APPLICATION V}

6835 0J Analysis of the thermal stress of IRFPA assembly using FEM [6835-80]

H. Zhang, H. Lu, Shanghai Institute of Technical Physics (China)

6835 OK The device for observing the solar on moon in multispectrum [6835-94]

G. Huang, Q. Xiao, C. Zheng, K. Chu, Z. Jin, Beijing Institute of Technology (China)

$6835 \mathrm{OL}$ The electronic structure of the PbS(-100) with vacancy defect: first-principles study [6835-21]

Z.-L. Ding, H.-Z. Xing, Donghua Univ. (China); Y. Huang, X.-S. Chen, Shanghai Institute of Technical Physics (China)

$68350 \mathrm{M}$ Generation of ultrashort mid-infrared pulses by super continuum seeded OPA in a MgO: $\mathrm{LiNbO}_{3}$ crystal [6835-83]

Y. Deng, Q. Zhu, X. Zeng, Y. Zhang, X. Wang, F. Wang, X. Huang, X. Xie, Y. Zuo, Research Ctr. of Laser Fusion (China)

$68350 \mathrm{~N}$ Progress in cooled IR detectors and new developments [6835-85]

P. Tribolet, M. Vuillermet, Sofradir (France)

\section{INFRARED IMAGERS/SYSTEMS AND THEIR APPLICATION I}

683500 Subpixel boundary backward substitution reconstruction algorithm for not uniform microscan to FPA and blind micromotion matching [6835-13]

Y. Chen, W. Jin, L. Zhao, M. Gao, L. Zhao, Beijing Institute of Technology (China) 
6835 OP Analysis of selection of structural element in mathematical morphology with application to infrared point target detection [6835-16]

J. Guo, Shanghai Institute of Technical Physics (China) and Graduate School of the Chinese Academy of Sciences (China); G. Chen, Shanghai Institute of Technical Physics (China)

$68350 Q \quad$ Infrared dual spectral imaging system [6835-17]

H. Wang, A. Geng, C. Yang, Q. Cao, L. Guo, Huazhong Institute of Electro-Optics (China)

6835 OR MODIS-based analysis of snow distribution and change in Emin River basin, Xinjiang, China [6835-19]

Z. Liu, China Univ. of Mining and Technology (China), Xinjiang Univ. (China), International Ctr. for Desert Affairs (China), and Xinjiang Key Subject of Ecology (China); J. Gao, China Univ. of Mining and Technology (China); H. Pei, S. Fang, Xinjiang Univ. (China)

\section{INFRARED IMAGERS/SYSTEMS AND THEIR APPLICATION II}

6835 OS General performance evaluation on thermal imaging systems with the square integral method based on MRTD channel width [6835-28]

J. Wang, W. Jin, X. Wang, L. Wang, Beijing Institute of Technology (China)

6835 OT Study of dynamic infrared scene projection technology based on digital micro-mirror device (DMD) [6835-57]

Y. Hu, J. Gao, J. Wang, Y. Zheng, J. Wang, J. Xie, Xi'an Institute of Applied Optics (China)

6835 OU Study on pulsed phase analysis of depth measurement for infrared thermal wave nondestructive evaluation [6835-69]

Y. Li, Y. Zhao, Beijing Institute of Technology (China); L. Feng, C. Zhang, Capital Normal Univ. (China)

\section{INFRARED IMAGERS/SYSTEMS AND THEIR APPLICATION III}

$68350 \mathrm{~V} \quad$ Ultrasonic infrared thermal wave nondestructive evaluation for crack detection of several aerospace materials [6835-71]

W. Xu, J. Shen, C. Zhang, N. Tao, L. Feng, Capital Normal Univ. (China)

6835 OX Optical path layout and moving mirrors of wavemeter based on Michelson interferometer [6835-89]

L. Wang, Tianjin Univ. of Technology and Education (China); Y. Peng, Beijing Univ. of Technology (China); F. Gao, Y. He, H. Zheng, Tianjin Univ. of Technology and Education (China)

683510 MTF testing algorithms for sampled thermal imaging systems [6835-86]

S. D. Fantone, D. A. Imrie, D. Orband, J. Zhang, Optikos Corp. (USA) 
683512 Quantitative analysis of peanut oil content in ternary blended edible oil using near infrared spectroscopy [6835-101]

H. Chen, F. Liu, Z. Wang, S. Jin, China Jiliang Univ. (China)

683513 Calibration research of laser speedometer [6835-107]

Y. Cui, T. Li, J. Leng, H. Shi, Changcheng Institute of Metrology and Measurement (China)

683514 Infrared and visible image fusion algorithm based on Contourlet transform and PCNN [6835-02]

Y. Lin, L. Song, X. Zhou, Y. Huang, Tianjin Univ. (China)

683515 Technology for low-cost PIR security sensors [6835-97]

K. C. Liddiard, Electro-optic Sensor Design (Australia)

\section{POSTER SESSION}

683516 High uniformity InGaAs linear mesa-type SWIR focal plane arrays [6835-03]

H. Tang, X. WU, K. Zhang, Shanghai Institute of Technical Physics (China) and Graduate School of the Chinese Academy of Sciences (China); L. Ye, N. Wang, X. Li, H. Gong, Shanghai Institute of Technical Physics (China)

683517 Iterative infrared image restoration [6835-06]

T. Si, J. Qiao, Y. Gao, Nanyang Institute of Technology (China) and Nanjing Univ. of Science and Technology (China); B. Chang, Nanjing Univ. of Science and Technology (China)

683518 A kind of real-time infrared image enhancement algorithm [6835-07]

T. Si, Y. Gao, J. Qiao, Nanyang Institute of Technology (China) and Nanjing Univ. of Science and Technology (China); B. Chang, Nanjing Univ. of Science and Technology (China)

683519 Growth and characterization of $\langle 110\rangle$ oriented ZnTe single crystal [6835-08]

R. Wang, W. Fang, P. Zhao, Shanghai Institute of Technical Physics (China); C. Zhang, Nanjing Univ. (China); L. Zhang, J. Ge, S. Yuan, H. Zhang, S. Hu, X. Shen, N. Dai, Shanghai Institute of Technical Physics (China)

$68351 \mathrm{~A}$ Application of contourlet transform in infrared image denoising [6835-10] Y. Lin, X. Zhou, L. Song, Y. Huang, Tianjin Univ. (China)

6835 1B Study on the thermal field change and affecting factors in urban areas of Hangzhou tourism city [6835-11]

Q. Cheng, X. Wu, Zhejiang Gongshang Univ. (China)

6835 1C Retrieval of atmospheric water content and transmittance computation of thermal bands based on MODTRAN [6835-12]

Q. Cheng, X. WU, Zhejiang Gongshang Univ. (China)

6835 1D Fast curvelet transform based non-uniformity correction for IRFPA [6835-20]

L. Dong, W. Jin, X. Zhou, Beijing Institute of Technology (China) 
$6835 \mathrm{IE}$ The distribution of grating-coupled field of quantum well infrared photodetector using FDTD method [6835-25]

H. Chen, X. Chen, Shanghai Institute of Technical Physics (China); Y. Zeng, Shanghai Institute of Technical Physics (China) and Royal Institute of Technology (Sweden); Z. Li, D. Xiong, W. Lu, Shanghai Institute of Technical Physics (China)

$6835 \mathrm{IF} \quad$ An optical model of wide field of view superspectral imager [6835-33]

Z. He, W. Xu, J. Jia, R. Shu, J. Wang, Shanghai Institute of Technical Physics (China)

$68351 G$ The research for a system of binocular stereo vision based on the near-infrared imaging characteristics of black-and-white CCD [6835-34]

P. Zhang, Z. Zhang, Y. Zhang, Academy of Armored Force Engineering (China)

$6835 \mathrm{1H}$ Study on the predicted model of crop leaf water status by the NIR band of ground reflectance and spaceborne hyperspectral images [6835-38]

Q. Jiao, X. Liu, B. Liu, Institute of Remote Sensing Applications (China) and Graduate School of Chinese Academy of Sciences (China); X. Zhang, Graduate School of Chinese Academy of Sciences (China); B. Zhang, Ctr. for Earth Observation and Digital Earth (China)

$68351 \mathrm{~J}$ IMMPDA algorithm for infrared target tracking based on multifeature fusion [6835-43] J. Zhang, J. Song, Institute of Optics and Electronics (China) and Graduate Univ. of the Chinese Academy of Sciences (China); Q. Wu, Institute of Optics and Electronics (China)

6835 1K New technology of photoelectric reconnaissance based on exploitation of quantum effects [6835-44]

K. Yang, L. Chen, H. Liu, China Jiliang Univ. (China)

$6835 \mathrm{IL} \quad$ Automatic target detection in dual band infrared imagery [6835-45]

J. Yu, Graduate School of Chinese Academy of Sciences (China) and Shanghai Institute of Technical Physics (China); S. Sun, G. Chen, Shanghai Institute of Technical Physics (China)

$68351 \mathrm{M}$ The side-passivation research on LWIR HgCdTe detector [6835-46]

Q. XU, H. Tang, Shanghai Institute of Technical Physics (China) and Graduate School of the Chinese Academy of Sciences (China); H. Gong, Shanghai Institute of Technical Physics (China)

6835 IN Pseudo-color coding method of infrared images based on human vision system [6835-49] X. Zhang, T. Bai, H. Li, Beijing Institute of Technology (China)

683510 Research of sub-pixel location algorithm based on image correlation [6835-52]

F. Li, C. XU, W. Jin, X. Wang, Beijing Institute of Technology (China)

6835 IP A novel infrared image fusion algorithm based on contourlet transform [6835-54] Y. Song, K. Gao, G. Ni, Beijing Institute of Technology (China)

$68351 Q \quad$ Infrared dim small target track predicting using least squares support vector machine [6835-58]

G. Wang, K. Gao, G. Ni, Beijing Institute of Technology (China) 
6835 is A preliminary study on laser-induced damage in InGaAs material and detectors [6835-64] H. Liu, H. Tang, H. Gong, Shanghai Institute of Technical Physics (China)

6835 IT Characterization of multilayered HgCdTe for MW/LW two-color application [6835-72] Q. Wei, W. Zhou, Shanghai Institute of Technical Physics (China) and Graduate Univ. of Chinese Academy of Sciences (China); W. Wang, Shanghai Institute of Technical Physics (China); X. Fu, Shanghai Institute of Technical Physics (China) and Graduate Univ. of Chinese Academy of Sciences (China); M. YU, L. Chen, Y. Wu, L. He, Shanghai Institute of Technical Physics (China)

$68351 \mathrm{U} \quad$ Surface defects induced by impurities in MBE-grown HgCdTe [6835-73]

X. Fu, Shanghai Institute of Technical Physics (China) and Chinese Academy of Sciences (China); W. Wang, Shanghai Institute of Technical Physics (China); Q. Wei, Shanghai Institute of Technical Physics (China) and Chinese Academy of Sciences (China); J. Wu, L. Chen, Y. Wu, L. He, Shanghai Institute of Technical Physics (China)

$68351 \mathrm{~V}$ The research of range-gated laser night vision system on cars [6835-77] Z. Zeng, H. Fan, S. Hejun, Institute of Semiconductors (China)

6835 IW Infrared target tracking using multisensor data fusion [6835-78]

J. Zhang, Y. LU, H. Zhu, Institute of Optics and Electronics (China) and Graduate Univ. of the Chinese Academy of Sciences (China); Q. Wu, Institute of Optics and Electronics (China)

$68351 \mathrm{X}$ Analysis of thermal stress damage in single-crystal silicon induced by 1064-nm long-pulse laser [6835-87]

Y. Chen, J. Lu, X. Ni, Nanjing Univ. of Science and Technology (China)

$68351 Y \quad$ A robust sub-pixel edge detection method of infrared image based on tremor-based retinal receptive field model [6835-90]

K. Gao, H. Yang, X. Chen, G. Ni, Beijing Institute of Technology (China)

$68351 \mathrm{~F}$ Fast response pyroelectric detector-preamplifier assembled device [6835-91]

P. Bai, Y. Tai, H. Liu, Kuming North Infrared Science and Technology Co. Ltd. (China)

683520 Study of uncooled thermal imaging system with multiple working temperatures [6835-96] J. Zhang, T. Si, L. Sun, B. Chang, Y. Qian, Y. Qiu, Nanjing Univ. of Science and Technology (China)

$683521 \quad$ Research on 10.6 m laser beam monitoring in $\mathrm{CO}_{2}$ laser processing system [6835-103] Y. Shi, Changchun Institute of Optics, Fine Mechanics and Physics (China) and Graduate School of the Chinese Academy of Sciences (China); Y. Gao, Changchun Institute of Optics, Fine Mechanics and Physics (China); W. Deng, S. Shao, Changchun Institute of Optics, Fine Mechanics and Physics (China) and Graduate School of the Chinese Academy of Sciences (China) 
683522 Based on Householder transform of the Zernike polynomial wavefront fitting method to solve active optics correction force [6835-104]

F. Wang, Changchun Institute of Optics, Fine Mechanics and Physics (China) and Graduate School of the Chinese Academy of Sciences (China); F. Yang, Changchun Institute of Optics, Fine Mechanics and Physics (China); X. Wu, Changchun Institute of Optics, Fine Mechanics and Physics (China) and Graduate School of the Chinese Academy of Sciences (China); H. Liu, Changchun Institute of Optics, Fine Mechanics and Physics (China)

$68352 \mathrm{E}$ Design of a recursive filter for infrared image real-time processing [6835-70]

B. Zhou, Z. Zhou, Y. He, Ordnance Engineering College (China)

$68352 \mathrm{H} \quad$ Application of improved BP neural network in infrared spectroscopy [6835-92] M. Gao, H. Zhang, S. Jin, China Jiliang Univ. (China)

$68352 \mathrm{~L} \quad$ A novel real-time system for driving an infrared focal plan array based on FPGA [6835-04] E. Koohestani, Rayan-Electronic Fardo Co. (Iran); A. Homaei, Rayan-Electronic Fardo Co. (Iran) and Azad Univ. (Iran)

Author Index 
Downloaded From: https://www.spiedigitallibrary.org/conference-proceedings-of-spie on 26 Apr 2023

Terms of Use: https://www.spiedigitallibrary.org/terms-of-use 


\title{
Conference Committee
}

\author{
Conference Chairs
}

Yi Cai, Kunming Institute of Physics (China)

Haimei Gong, Shanghai Institute of Technical Physics (China)

Jean-Pierre Chatard, ULIS (France)

Program Committee

Yuping Cui, Tianjin Jinhang Institute of Technical Physics (China)

Jianzhong Han, North China Research Institute of Electro-Optics

(China)

Hui Huang, Kunming Institute of Physics (China)

Weiqi Jin, Beijing Institute of Technology (China)

Yongzhi Liu, University of Electronic Science and Technology of China

(China)

Jianyu Wang, Shanghai Institute of Technical Physics (China)

Session Chairs

1 Infrared Materials/Devices and Their Application I

Yi Cai, Kunming Institute of Physics (China)

Jean-Pierre Chatard, ULIS (France)

2 Infrared Materials/Devices and Their Application II

Yi Cai, Kunming Institute of Physics (China)

Jean-Pierre Chatard, ULIS (France)

3 Infrared Materials/Devices and Their Application III

Yi Cai, Kunming Institute of Physics (China)

Haimei Gong, Shanghai Institute of Technical Physics (China)

$4 \quad$ Infrared Materials/Devices and Their Application IV

Yi Cai, Kunming Institute of Physics (China)

Haimei Gong, Shanghai Institute of Technical Physics (China)

5 Infrared Materials/Devices and Their Application V

Yi Cai, Kunming Institute of Physics (China)

6 Infrared Imagers/Systems and Their Application I

Yi Cai, Kunming Institute of Physics (China) 
7 Infrared Imagers/Systems and Their Application II François Simoens, Commissariat à l'Energie Atomique (France) Yi Cai, Kunming Institute of Physics (China)

8 Infrared Imagers/Systems and Their Application III François Simoens, Commissariat à l'Energie Atomique (France) Yi Cai, Kunming Institute of Physics (China)

9 Infrared Imagers/Systems and Their Application IV Haimei Gong, Shanghai Institute of Technical Physics (China) Yi Cai, Kunming Institute of Physics (China) 


\title{
Symposium Committees
}

\author{
General Chairs \\ Brian Culshaw, University of Strathclyde (United Kingdom) \\ Bingkun Zhou, Tsinghua University (China) and COS-Chinese Optical \\ Society (China) \\ General Cochairs
}

Arthur Chiou, National Yang-Ming University (Taiwan, China)

Mitsuo Takeda, University of Electro-Communications (Japan)

Chungli Bai, Chinese Academy of Sciences (China)

Seung-Han Park, Yonsei University (South Korea)

Zhizhan Xu, Shanghai Institute of Optics and Fine Mechanics

(China)

Jianlin Cao, China Ministry of Science and Technology (China)

Junhao Chu, Shanghai Institute of Technical Physics (China)

Jingming Kuang, Beijing Institute of Technology (China)

Xiaomin Ren, Beijing University of Posts and Telecommunications (China)

Dingbo Kuang, Shanghai Institute of Technical Physics (China)

Guozheng Yang, Institute of Physics (China)

Honorary Chairs

Daheng Wang, Chinese Academy of Sciences (China)

Guoguang Mu, Nankai University (China)

Technical Program Chair

Songlin Zhuang, Shanghai University of Science and Technology (China)

Technical Program Cochairs

Xun Hou, Xian Institute of Optics and Precision Mechanics (China)

Qian Mao, Wuhan Research Institute of Posts and Telecommunications (China)

Xu Liu, Zhejiang University (China)

Local Organizing Committee Chair

Shusen Xie, Fujian Normal University (China)

Local Organizing Committee Cochairs

Guoqiang Ni, Beijing Institute of Technology (China)

Qihuang Gong, Peking University (China)

Ying Gu, PLA General Hospital (China)

Huilin Jiang, Changchun University of Science and Technology (China) 
General Secretary

Guoqiang Ni, Beijing Institute of Technology (China)

Administrative Vice General Secretary

Boyu Ding, Beijing Institute of Technology (China)

Vice General Secretaries

Hanyi Zhang, Tsinghua University (China)

Ya Cheng, Shanghai Institute of Optics and Fine Mechanics (China)

Zhongwei Fan, Academy of Opto-electronics (China)

Jianxin Chen, Fujian Normal University (China)

Lan Wu, Zhejiang University (China)

Shaowen Wang, COS-Chinese Optical Society (China)

Yuejin Zhao, Beijing Institute of Technology (China)

Chongxiu Yu, Beijing University of Posts and Telecommunication (China)

Jun Ruan, China Solid State Lighting Research and Industry Alliance

(China)

Local Organizing Committee Members

Kangnan Qi, Beijing Optical Society (China)

Chunqing Gao, Beijing Institute of Technology (China)

Tiegen Liu, Tianjin University (China)

Lanxing Shao, Shanghai Optical Society (China)

Zaixuan Zhang, Chinese Jiliang University (China)

Hongda Chen, Institute of Semiconductors (China)

Baosheng Liu, Beijing Optical Society (China)

Xin Wang, Hubei Optical Society (China)

Lin Zhai, COS-Chinese Optical Society (China)

Zhiqiang Zhu, East China Normal University (China)

Lei Xu, Fudan University (China)

Hezhou Wang, Zhongshan University (China)

Zhiming Yi, Ofstar Tech Company, Ltd., Shenzhen (China) 